\title{
Correlates of Actual and Self-Reported Knowledge and Skills, Attitudes, and Barriers Mitigating Against the Implementation of Evidence-Based Practice in Physiotherapy
}

\author{
Joseph A. Balogun, Chidozie E. Mbada, Adetoyeje Y. Oyeyemi, Faith A. Awoleye, \\ David B. Olakorede, and Adetutu O. Balogun
}

\section{ABSTRACT}

\begin{abstract}
Background: Evidence-based practice (EBP) has in the last decade gained global prominence in healthcare professions including physiotherapy. Several studies have been conducted worldwide to determine physiotherapists' knowledge, attitudes, beliefs, behaviors, skills, and resources, and barriers mitigating against the implementation of EBP in physical therapy, but there is limited information on the correlation among actual (competence) and self-report (perceived) knowledge and skills about EBP.
\end{abstract}

Methods: This cross-sectional study investigated the premise of these associations among 233 Nigerian physiotherapists who completed a previously validated 55 -item questionnaire that assessed demographic data, actual and self-report knowledge, skills and resources, attitudes, and barriers about EBP.

Result: We found no significant relationship between actual knowledge of EBP and clinical experience $(r=.086, p>.05)$, age $(r=.048, p>.05)$, academic degree $(r=.108, p>.05)$, self-reported knowledge $(r=.097, p>.05)$, and selfreported skills about EBP $(r=.095$, $p>.05)$. Demographic variables (age, years of clinical experience, and academic degrees) and psychosocial factors (selfreported knowledge, skills and resources, attitudes, and barriers about EBP) are not a significant predictor of actual knowledge of EBP.

Conclusion: The physiotherapists perceived that they are competent about EBP but in reality, they are not, and may fail to seek educational resources that will improve their understanding and improve their skills about EBP.

Keywords: Evidence-based practice, Competence, Self-report,
Physiotherapist.

Submitted : February 2, 2021

Published : March 3, 2021

ISSN: 2593-8339

DOI: $10.24018 /$ ejmed.2021.3.2.704

Distinguish Professor Joseph A. Balogun*

Chicago State University, USA

(e-mail: jbalogun@csu.edu)

Dr. Chidozie E. Mbada

Obafemi Awolowo University, Nigeria.

(e-mail: doziembada@yahoo.com)

Professor Adetoyeje Y. Oyeyemi

Department of Medical Rehabilitation, University of Maiduguri, Nigeria.

(e-mail: adeoyeyemi@aol.com)

Faith A. Awoleye

Obafemi Awolowo University, Nigeria.

(e-mail: faithawoleye@gmail.com)

David B. Olakorede

Obafemi Awolowo University, Nigeria.

(e-mail: dolakorede@ gmail.com)

Dr Adetutu O. Balogun

Joseph Rehabilitation Center, USA.

(e-mail: tutubalogunotd ${ }^{\circledR}$ gmail.com)

*Corresponding Author

\section{INTRODUCTION}

Evidence-based practice (EBP) has in the last decade gained global prominence in healthcare professions because it provides the framework for lifelong and self-directed learning; traits that are crucial for the continued provision of quality health care. Sackett and associates [1] defined EBP as the integration of best research evidence with clinical expertise and patient values' to improved patient outcomes. The roots of EBP started over 3,000 years ago in Egypt with crude experiments to test the effectiveness of bloodletting. Several studies [2]-[13] have been conducted in different countries worldwide to determine physiotherapists' selfreported knowledge, skills, resources, beliefs, attitudes, behaviors, and barriers mitigating against the implementation of EBP in physical therapy.

Only the study by Alshehri and associates [13] from Saudi Arabia assessed both the actual knowledge (competence) and perceived (self-report) knowledge of EBP. Their study found that the vast majority of the physiotherapists overrated their knowledge about EBP. About $65 \%$ and $61 \%$ of the study participants self-reported that they "completely or very well" understood the meaning of the terms "systematic review" and "randomized controlled trial," respectively. On the other hand, only $10 \%$ of the respondents were able to correctly defined EBP, $19 \%$ correctly understood the purpose of EBP and $32 \%$ were aware that EBP implementation required an extended period for EBP implementation.

The findings in previous studies on self-reported knowledge of EBP among physiotherapists should be applied with caution because existing literature in education and marketing have firmly established that self-reported (perceived) knowledge and actual (competence) knowledge are distinctly different constructs [14], [15]. In a meta-study, Sitzmann and associates [15] found a correlation of .34 between self-reported (perceived) knowledge and actual 
knowledge. However, the association was zero between selfreported knowledge gain (perceived learning) and actual knowledge. Thus, physiotherapists who perceive that they are competent about EBP may be unaware of their limited knowledge and thus unlikely to seek educational training that will improve their understanding and skills about EBP [16]. This schism and potential misperception of EBP knowledge raise fundamental questions regarding the competence of physiotherapists in previous studies [2]-[13]. Given the existing evidence in the behavioural literature, the distinction between actual and self-report knowledge must be recognized and tested experimentally, to advance the understanding of physiotherapists' knowledge of EBP.

This study set out to investigate the relationship between physiotherapists' actual and self-reported knowledge and skills, attitudes, and barriers mitigating against the implementation of EBP in physical therapy. We hypothesized that physiotherapists who perceived that they are knowledgeable about EBP may likely have overrated their competence. Thus, we expect a weak correlation between self-reported knowledge/skills and actual knowledge of EBP.

\section{METHODOLOGY}

\section{A. Research Design and Sample Size Estimation}

This correlational study was conducted among members of the Nigeria Society of Physiotherapy. We determined the sample size for a hypothetical correlation coefficient of 0.41 (moderate correlation), set at an alpha (two-tailed) level of 0.05 (threshold probability to reject the null hypothesis - Type I error rate) and $\beta$ (the likelihood of failing to reject the null hypothesis under the alternative hypothesis - Type II error rate) at 0.01 . Under these set experimental design conditions, a minimum sample size of 100 subjects will be required as derived by the UCSF online calculators [17].

\section{B. Measuring Instrument}

The 55-item EBP Inventory developed by Balogun and associates [18] was used in this study. The inventory consisted of seven parts - sociodemographic, EBP competence, and behaviors, perceived knowledge of EBP, perceived skills and resources, attitudes about EBP, and barriers related to the use of EBP. The sociodemographic information sought includes age, number of years of clinical experience, gender, marital status, and highest education, place of employment, clinical specialty area, and employment setting. Part 2 of the instrument contained eleven multiplechoice questions designed to assess respondents' actual knowledge (i.e., competence) of EBP. Each item has a "Yes," "No," or "Don't Know" response option. The minimum competence score is zero and the maximum possible score is 11. A high aggregate score indicates that the respondent is very knowledgeable (competent) about EBP.

The items in Part 3 consists of four multiple-choice questions about strategies used for updating self professionally, the database used by respondents for literature search, the frequency of database used in the last six months, and where respondents undertake database search. Part 4 of the instrument is on perceived (self-report) knowledge of EBP. It consists of seven items on which respondents were instructed to indicate their opinion on a five-point Likert scale (where one=strongly disagree, two=partially disagree, three $=$ neutral, four $=$ partially agree, and five $=$ strongly agree) . The minimum and the maximum possible score is 7 and 35 , respectively. A high aggregate score indicates the individual considers him/herself to be knowledgeable about EBP. Part 5 is on perceived (self-report) skills and resources and consists of eight items on which the study participants were instructed to indicate their opinion on a 5-point Likert scale (where one $=$ strongly disagree, two $=$ partially disagree, three $=$ neutral, four=partially agree, and five $=$ strongly agree).

The minimum and the maximum possible score is 8 and 40 , respectively. A high aggregate score indicates the individual considers him/herself to have skills and infrastructures to engage in EBP. Part 6 is on attitudes about EBP and consists of five items on which respondents were instructed to indicate their opinion on a five-point Likert scale (where 1 =strongly disagree, 2 =partially disagree, $3=$ neutral, $4=$ partially agree, and 5=strongly agree. A high aggregate score indicates the individual considers him/herself to be knowledgeable about EBP. Part 7 is on barriers-related to the use of EBP, and it consists of nine items on which respondents were instructed to indicate Yes or No. The minimum and the maximum possible score is 1 and 10 , respectively. A high aggregate score suggests the individual has high barriers to the use of EBP.

Balogun and associates [18] previous study revealed the instrument is relatively easy to comprehend, highly stable, and internally consistent. The Flesch-Kincaid Reading Ease and Flesch-Kincaid scores for the instrument were 49.5 and 8.3 , respectively. Three of the instrument's seven component parts showed "almost perfect" (ICC $=0.4-0.6 ; \mathrm{p}<0.001$ ) correlation and another three parts showed "substantial" (ICC $=0.6-0.8 ; \mathrm{p}<0.001)$ correlations. Only one of the parts (search engine used in EBP) showed poor correlation. The Cronbach's alpha for actual knowledge (competence) on EBP was $0.837,0.703$ for strategies to upgrade the level of professionalism, 0.333 for search engine use in EBP, 0.619 for perceived (self-report) of EBP, 0.761 for perceived (selfreport) skills, and resources in EBP, 0.803 for attitudes about EBP and 0.814 for barriers-related to EBP.

\section{Procedure}

Two hundred and forty-seven physiotherapists participated in the study. However, only the data of 233 respondents was complete and valid for analysis. All grades of licensed physiotherapists with full-time employment in the clinical and academic settings were purposively recruited from the country's six geopolitical zones. Recent graduates and those with less than a year of clinical experience and employed part-time were excluded from the study. Following the participating subjects' recruitment, they were briefed of the study's objectives, and informed consent was obtained. Anonymity was guaranteed for the respondents. Participation was voluntary, and the subjects were instructed to answer the questions as honestly and as accurately as possible. Subsequently, the instrument was administered to the study participants with no time limit imposed to complete the survey. Most subjects completed it within 20-25 minutes.

The same research staff members administered the inventory in each of the selected tertiary hospitals. No stipends or incentive was offered for participating in this 
study. For test-retest matching purposes, the respondents' date of birth and different color papers were used during the data entry and data analysis to identify each respondent.

\section{Ethical Approval}

The Ethics Committee at the College of Medical Sciences, University of Maiduguri, Nigeria approved the protocol for this investigation.

\section{E. Statistical Analysis}

We analyzed the data collected with the Statistical Package for Social Scientists (SPSS) computer-based software, version 16. Raw data were crosschecked by running frequency distribution for accuracy before statistical analysis. We computed the Spearman, Pearson's' product-moment correlation coefficients to explore relationships between the ordinal and interval/ratio data, respectively. We explored the effect of age, clinical experience, and highest education on actual knowledge of EBP using the multi-regression analysis model. A statistically significant difference was set at an alpha level of 0.05 . We used the guidelines proposed by Landis and Koch [19] to interpret the reliability data. They described an agreement level between $0-0.2$ as "poor," $0.2-$ 0.4 "fair," 0.4-0.6 "moderate," 0.6-0.8 "substantial," and 0.8-0.9 "almost perfect."

\section{RESULTS}

The majority of the respondents $(64.2 \%)$ were males and $35.8 \%$ females with a mean age of $34.6 \pm 8.2$ years. The participants between 30-39 years of age are the majority in the study (46.7\%). Respondents $(87.4 \%)$ with less than ten years of clinical experience, as well as those with a bachelor's degree as the highest qualification $(54.1 \%)$, formed the majority of the study participants. As a group, their average years of clinical experience was $10.1 \pm 7.5$ years. The average age and years of clinical experience for the physiotherapists were 34.6 $\pm 8.2(\mathrm{CI}=33.4-35.8)$ and $10.2 \pm 7.6(\mathrm{CI}=9.1-11.3)$ years, respectively (Table 1). The average actual knowledge (performance on a competency test) of EBP was $68.5 \pm 16.1 \%$ $(\mathrm{CI}=66.1-70.9)$. The majority of the physiotherapists $(29.8 \%)$ reported "attending conferences and continuing education workshops" as the primary strategy for upgrading themselves professionally.

TABLE 1: PHySIOTHERAPISTS AgE, CliniCAL EXPERIENCE, AND PERFORMANCE ON AN EVIDENCE-BASED PRACTICE COMPETENCY TEST (\%)

\begin{tabular}{cccccc}
\hline Variable & Minimum & Maximum & Mean & SD & $95 \%$ CI \\
\hline Age & 21 & 65 & 34.6 & 8.2 & $33.4-35.8$ \\
$\begin{array}{c}\text { Clinical experience } \\
\text { (years) }\end{array}$ & 1 & 40 & 10.2 & 7.6 & $9.1-11.3$ \\
$\begin{array}{c}\text { Actual knowledge of } \\
\text { EBP }(\%)\end{array}$ & 18.2 & 100 & 68.5 & 16.1 & $66.1-70.9$ \\
\hline
\end{tabular}

The descriptive statistics for the major components of the EBP factors are presented in Table 2. The average selfreported knowledge of EBP $(* / 35)$ was $25.8 \pm 5.42$, selfreported skills and resources in EBP $(* / 40)$ was $28.7 \pm 5.32$, attitudes about $\operatorname{EBP}(* / 30)$ and barriers-related to $\operatorname{EBP}(* / 10)$ was $2.97 \pm 2.06$.
TABLE 2: The PHysiotherapists' PerformanCE ON THE SEVEN MAJOR COMPONENTS OF THE EBP INVENTORY

\begin{tabular}{|c|c|}
\hline Instrument parts & Mean \\
\hline & $\mathrm{M} \pm \mathrm{SD}$ \\
\hline $\begin{array}{l}\text { Strategies to upgrade the level of } \\
\text { professionalism }(* / 5)\end{array}$ & $3.95 \pm 0.22$ \\
\hline The search engine used in $\operatorname{EBP}(* / 5)$ & $4.52 \pm 0.50$ \\
\hline Actual knowledge of EBP $(100 \%)$ & $68.5 \pm 16.1$ \\
\hline $\begin{array}{l}\text { Perceived (self-reported) knowledge of } \\
\operatorname{EBP}(* / 35)\end{array}$ & $25.8 \pm 5.42$ \\
\hline $\begin{array}{l}\text { Perceived (self-reported) skills and } \\
\text { resources in } \operatorname{EBP}(* / 40)\end{array}$ & $28.7 \pm 5.32$ \\
\hline Attitudes about EBP $(* / 30)$ & $21.1 \pm 3.58$ \\
\hline Barriers-related to $\operatorname{EBP}(* / 10)$ & $2.97 \pm 2.06$ \\
\hline
\end{tabular}

The percentile score for the physiotherapist's age, years of clinical experience, and actual knowledge of EBP are presented in Table 3. The median age of the physiotherapists was 34 years and nine years for clinical experience. Similarly, their median performance score on the EBP competency test was $72.7 \%$.

TABLE 3: The Percentile SCORE For the Physiotherapists' Age, ClinICAL EXPERIENCE, AND ACTUAL KNOWLEDGE OF THE EVIDENCEBASED PRACTICE

\begin{tabular}{cccccccc}
\multicolumn{8}{c}{ BASED PRACTICE } \\
\hline Variable & $\begin{array}{c}\text { Percentile } \\
5 \text { th }\end{array}$ & 10 th & 25 th & 50 th & 75 th & 90 th & 95 th \\
\hline $\begin{array}{c}\text { Age (years) } \\
\text { Clinical } \\
\text { experience } \\
\quad \text { (years) } \\
\begin{array}{c}\text { Actual } \\
\text { Knowledge of } \\
\text { EBP (\%) }\end{array}\end{array}$ & 23.0 & 25.0 & 29.0 & 34.0 & 39.0 & 45.0 & 50.9 \\
\hline
\end{tabular}

The result of the correlation coefficients presented in Table 4 showed no significant relationship between actual knowledge of EBP and clinical experience $(r=.086, p>.05)$, age $(r=.048, p>.05)$, academic degree $(r=.108, p>.05)$, selfreported knowledge $(\mathrm{r}=.097, \mathrm{p}>.05)$, self- reported skills about $\operatorname{EBP}(\mathrm{r}=.095, \mathrm{p}>.05)$. However, the correlation between actual knowledge of EBP and attitudes towards EBP were low but statistically significant $(\mathrm{r}=.165, \mathrm{p}<.05)$. The findings also revealed that self-reported knowledge of EBP was significantly related to clinical experience $(\mathrm{r}=.303$, $\mathrm{p}<.001 ;$ age $(\mathrm{r}=.323, \mathrm{p}<.001)$ and academic degree $(\mathrm{r}=.340$, $\mathrm{p}<.001)$.

As expected, clinical experience was significantly related to age $(\mathrm{r}=.896, \mathrm{p}<.001)$, and academic degrees $(\mathrm{r}=465$, $\mathrm{p}<.001)$. In addition, age and academic degree was significantly related $(\mathrm{r}=435, \mathrm{p}<$. 001). Self-reported knowledge is also significantly related to self-reported skill $(r=.309, p<$. 001). Barriers associated with EBP is significantly related to academic degree $(r=.140, p<.05)$, self-reported knowledge $(r=.145, p<.05)$, self-reported skill $(\mathrm{r}=.200, \mathrm{p}<.001)$ and attitude towards $\operatorname{EBP}(\mathrm{r}=.129, \mathrm{p}<.05)$. Attitudes about EBP is correlated to self-reported knowledge about EBP $(r=.240, \mathrm{p}<.001)$ and self-reported skill about $\operatorname{EBP}(\mathrm{r}=.358, \mathrm{p}<.001)$.

The result of the multi-regression analysis presented in Table 5 revealed that demographic variables (age, years of clinical experience, academic degrees) and psychosocial factors (self-reported knowledge, skills and resources, attitudes, and barriers about EBP) are not a significant predictor of the actual performance on the EBP competency test $(\mathrm{F}=.996, \mathrm{p}>.05)$. 
TABLE 4: CORRELATION MATRIX SHOWING RELATIONSHIPS BETWEEN THE DIFFERENT VARIABLES

\begin{tabular}{|c|c|c|c|c|c|c|c|c|}
\hline & $\begin{array}{l}\text { Clin. } \\
\text { Exp. }\end{array}$ & Age & Degree & $\begin{array}{c}\text { Perceived } \\
\text { Knowledge }\end{array}$ & $\begin{array}{c}\text { Perceived } \\
\text { Skill } \\
\end{array}$ & $\begin{array}{c}\text { Attitude } \\
\text { EBP }\end{array}$ & $\begin{array}{c}\text { EBP } \\
\text { Barriers } \\
\end{array}$ & $\begin{array}{l}\text { Actual EBP } \\
\text { Knowledge } \\
\end{array}$ \\
\hline Clinical Experience & 1 & $.896^{* *}$ & $.465 * *$ & $.303^{* *}$ & -.017 & .005 & .120 & .086 \\
\hline Academic degree & & & 1 & $.340 * *$ & .095 & -.026 & $.140 *$ & .108 \\
\hline Perceived Knowledge & & & & 1 & $.309 * *$ & $.240 * *$ & $.145^{*}$ & .097 \\
\hline Perceived Skill & & & & & 1 & $358 * *$ & $.200 * *$ & .095 \\
\hline
\end{tabular}

$* \mathrm{p}<.05 ; *{ }^{*} \mathrm{p}<.001$

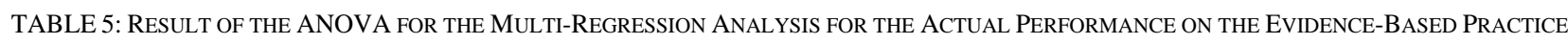

\begin{tabular}{ccccccc}
\hline \multicolumn{8}{c}{ COMPETENCY TEST } \\
\hline & Model & Sum of Squares & df & Mean Square & F & Sig. \\
\hline \multirow{2}{*}{1} & Regression & 1801.976 & 7 & 257.425 & .996 & $.436^{\mathrm{b}}$ \\
& Residual & 44177.063 & 171 & 258.345 & & \\
& Total & 45979.039 & 178 & & & \\
\hline
\end{tabular}

a. Dependent Variable: Actual knowledge of EBP (\%)

b. Predictors: (Constant), Highest degree, Attitude about EBP, Barriers mitigating against the use of EBP, Clinical experience, Self-reported knowledge, Self-reported skills, and Age.

\section{DISCUSSION}

The primary objective of this non-intervention correlational study was to explore the relationship between self-reported and actual knowledge of EBP. We hypothesized a weak correlation between self-reported and actual knowledge of EBP. Our hypothesis was accepted because we found no significant correlation between actual knowledge of EBP and self-reported knowledge $(r=.097, p>.05)$ and selfreported skills about EBP $(r=.095, \mathrm{p}>.05)$. Our findings suggest that the physiotherapists in the study perceived that they are competent about EBP but in reality, they are not.

Our findings are consistent with the result of a previous study by Drass and associates [16] who compared the selfreported knowledge and the actual knowledge of diabetes mellitus among 184 registered nurses (RN) in a university teaching hospital. A Diabetes Self-Report Tool (DSRT) was used to assess the perception of diabetes knowledge, and a 45-item multiple-choice questionnaire was used to assess the actual level of diabetes knowledge (competence). The study demonstrated a low negative correlation $(r=-.360, p<.001)$ between perceived and actual knowledge of diabetes. Their finding suggests that the higher the perceived knowledge of diabetes, the less the nurses knew about diabetes. Thus, overrated their competence.

Our finding is discordant from the result of another correlational study conducted by Kupris and Gayla [20] who compared staff nurses' self-reported and actual knowledge of diabetes mellitus in a convenience sample of 60 staff nurses from a 248-bed suburban teaching hospital using DSRT. They found a low positive association $(r=.230, p<.05)$ between the self-reported knowledge and the actual knowledge scores. Given the inconsistent findings in the literature, further studies on the relationship between selfreported and actual knowledge of learning are needed.

The ex post facto analysis in this study revealed no significant relationship between actual knowledge of EBP and clinical experience $(r=.086, \mathrm{p}>.05)$, age $(\mathrm{r}=.048$, $\mathrm{p}>.05)$, academic degree $(\mathrm{r}=.108, \mathrm{p}>.05)$. These findings corroborate the findings by Kupris and Gayla [20] who found no significant correlation between numbers of years of experience as a practicing RN and the actual knowledge $(\mathrm{r}=.098, \mathrm{p}>.05)$, between the number of years as an RN and self-reported knowledge $(r=-.177, \mathrm{p}>.05)$, between the number of years employed and actual knowledge $(r=-.129$, $\mathrm{p}>.05$ ), and between self-reported knowledge and the number of years employed $(\mathrm{r}=-.168, \mathrm{p}>.05)$.

Paradoxically, our finding revealed that demographic variables such as age, years of clinical experience and academic degrees, and psychosocial factors (attitudes, barriers, self-reported knowledge, and skills about EBP) are not a significant predictor of the actual performance on the EBP competency test. This outcome did not support the findings by Nelson and Steele [21] who conducted a survey to identify the correlates of self-reported EBP use among mental health practitioners $(n=214)$ from 15 states employed in diverse clinical settings. They found taking a class in EBP, support of the clinical facility toward EBP, and the clinician attitudes toward intervention research were the three viable predictors of self-reported EBP use. Attitudes toward intervention research partially mediated the relationship between the clinical facility and EBP use. Negative attitudes toward intervention research partially mediated the relationship between clinician training and self-reported EBP use.

\section{A. Practical Implication}

The reliability of self-reported data is a familiar debate in survey research. For example, more than $40 \%$ of Americans attend church every week according to opinion polls. However, church records revealed that less than $22 \%$ attend church every week. In his seminal work titled "Everybody lies," Stephens-Davidowitz [22] deftly provided ample evidence that showed that "most people do not do what they say and do not say what they do." This line of reasoning raises the fundamental question: How accurate are self-reported data? Cook and Campbell [23] in their classic book published in 1979 posited that research subjects display the social desirability phenomenon by reporting what they perceive the researcher expects to find or say what reflects positively on their knowledge, abilities, beliefs, or opinions.

Another concern in psychology literature is whether subjects participating in research can accurately recall past behaviours because of the fallibility of human memory [24]. Sometimes research subjects "remember" events that never happened. Thus, undermine the reliability of self-reported data. Consequently, some researchers are suspicious and 
consider self-reported data as poor quality. Chan [25] adroitly argued that the so-called poor quality of self-reported data is unwarranted, and that social desirability does not happen all the time, as research subjects are generally truthful about their gender and ethnicity. Khoury and associates [26] also affirmed that the recall bias observed in epidemiological research is over-rated, but warned that their position may not be correct in educational and psychological studies.

\section{CONCLUSION}

The findings in this study implied that the physiotherapists perceived that they are competent about EBP but in reality, they are not. Thus, they overrated their ability and are unaware of their limited knowledge and skills about EBP. In practical terms, this cohort of physiotherapists may fail to seek educational resources that will improve their understanding and improve their skills about EBP.

\section{FUNDING}

The researchers did not receive any funding from agencies in the public, commercial, or not-for-profit sectors to implement this study.

\section{REFERENCES}

[1] Sackett DL, Rosenberg WM, Gray JM, Haynes RB, Richardson WS. Evidence-based medicine: what it is and what it isn't. British Medical Journal, 1996; 312: 71-72 https://www.physiopedia.com/Evidence_Based_Practice_(EBP).

[2] Jette DU., K. Bacon, C. Batty et al. Evidence-based practice: beliefs, attitudes, knowledge, and behaviors of physical therapists. Physical Therapy, 2003; 83(9): 786-805.

[3] Thyer BA. What is evidence-based practice? Brief Treatment and Crisis Intervention, 2004; 4(2):167-176.

[4] Iles R, Davidson M. Evidence-based practice: a survey of physiotherapists' current practice. Physiother Res Int, 2006; 11: 93103 https://onlinelibrary.wiley.com/doi/pdf/10.1002/pri.328.

[5] Grimmer-Somers K, Lekkas P, Nyland L, Young A, Kumar S. Perspectives on research evidence and clinical practice: a survey of Australian physical therapists. Physiother Res Int 2007;12:147-61.

[6] Akinbo S, Odebiyi D, Okunola T, Aderoba O. Evidence-based practice: knowledge, attitudes and beliefs of physiotherapists in Nigeria. Internet J Med Informatics, 2008; 4: 1-8.

[7] Fruth SJ, Van Veld RD, Despos CA, Martin RD, Hecker A, Sincroft EE. The influence of topic-specific, research-based presentation on physical therapists' beliefs and practices regarding evidence-based practice Physiotherapy Theory \& Practice, 2010; 26: 537-557.

[8] Da Silva TM, Costa C, Garcia AN, Costa LO. What do physical therapists think about evidence-based practice? A systematic review. Man Ther. 2014; 20(3):388-401. doi: 10.1016/j.math.2014.10.009.

[9] Ramírez-Vélez R, Correa-Bautista JE, Muñoz-Rodríguez DI, Ramírez L, González-Ruíz K, Domínguez-Sánchez MA, Durán-Palomino D, Girabent-Farrés M, Eugenia Flórez López M, Bagur-Calafat MC. Evidence-based practice: beliefs, attitudes, knowledge, and skills among Colombian physical therapists. Colomb Med (Cali), 2015; 46(1):

$33-40$ https://www.ncbi.nlm.nih.gov/pmc/articles/PMC4437285/.

[10] Silva TM, Costa L, Costa LO. Evidence-Based Practice: a survey regarding behavior, knowledge, skills, resources, opinions and perceived barriers of Brazilian physical therapists from São Paulo state. Braz J Phys Ther 2015; 19:294-303.

[11] Condon C, McGrane N, Mockler D, Stokes E. Ability of physical therapists to undertake evidence-based practice steps: a scoping $\begin{array}{lll}\text { review. } & \text { Physiotherapy, 2016; } & 102(1): 10-9 .\end{array}$ https://pubmed.ncbi.nlm.nih.gov/26404896/.

[12] Yahui HC. Knowledge, attitudes, and barriers towards evidence-based practice among physiotherapists in Malaysia. Hong Kong $\begin{array}{lllll}\text { Physiotherapy } & \text { Journal, } & 2017 ; & 37, & 10-18 \text { : }\end{array}$ https://www.sciencedirect.com/science/article/pii/S10137025163005 25?via\%3Dihub.
[13] Alshehri MA, Alalawi A, Alhasan H, Stokes E. Physiotherapists' behaviour, attitudes, awareness, knowledge and barriers concerning evidence-based practice implementation in Saudi Arabia: a crosssectional study. Int J Evid Based Healthcare, 2017; 15(3): $127-$ 141:https://www.ncbi.nlm.nih.gov/pmc/articles/PMC5592985/.

[14] Bacon DR. Reporting actual and perceived student learning in education research. Journal of Marketing Education, 2016; 38(1) 3-6.

[15] Sitzmann T, Ely K, Brown K, Bauer K. Self-assessment of knowledge: A cognitive learning or affective measure? Academy of Management Learning \& Education, 2010; 9(2), 169-191.

[16] Drass, J.A., Mulr-Nash, J., Boykin, P.C., Turek, J.M., \& Baker, K.L. Perceived and actual level of knowledge of diabetes mellitus among nurses. Diabetes Care, 1989; 12 (5), 351-56.

[17] Kohn, MA, Senyak J. Sample size calculators [website]. UCSF CTSI. 19 August 2020. https://sample-size.net/correlation-sample-size/.

[18] Balogun JA, Oyeyemi AY, Mbada CE, Awoleye FA, Olakorede DB, Balogun AO. Evidence-based practice knowledge, beliefs, attitudes, and behaviors: Assessing the readability, stability, and internal consistency of a psychometric instrument. Proceedings of the Nigerian Academy of Science (In press).

[19] Landis JR, Koch GG. The measurement of observer agreement for categorical data. Biometrics, 1977; 33, 159-174.

[20] Kupris, Gayla M. Perceived and actual level of knowledge of diabetes mellitus among nurses. master's Theses, 1991; 111:http://scholarworks.gvsu.edu/theses/111.

[21] Nelson TD, Steele RG. Predictors of practitioner self-reported use of evidence-based practices: practitioner training, clinical setting, and attitudes toward research. Adm Policy Ment Health, 2007; 34(4):31930 .

[22] Stephens-Davidowitz, S. Everybody lies: Big data, new data, and what the Internet can tell us about who we really are. 2017. New York, NY: Dey Street Books.

[23] Cook, TD, Campbell, DT. Quasi-experimentation: Design and analysis issues. Boston, MA: Houghton Mifflin Company, 1979.

[24] Loftus, E. The fiction of memory. Paper presented at the Western Psychological Association Convention. 2016. Long Beach, CA. https://westernpsych.org/wp-content/uploads/2016/08/WPAProgram-2016-4Web.pdf.

https://webfiles.uci.edu/eloftus/Loftus_Illusions_Goldsmiths_SkepIn q2016.pdf?uniq=-huvh2c.

[25] Chan, D. So why ask me? Are self-report data really that bad? In Charles E. Lance and Robert J. Vandenberg (Eds.), Statistical and methodological myths and urban legends: Doctrine, verity and fable in the organizational and social sciences, 2009; 309-335. New York NY: Routledge.

[26] Khoury M, James L, Erikson J. On the use of affected controls to address recall bias in case-control studies of birth defects. Teratology, 1994; 49, 273-281. 